\title{
非定常外源强迫下大尺度大气方程 组解的性质*
}

\author{
李建平 丑纪范
}

(兰州大学大气科学系, 兰州 730000)

\section{关键词 大气方程组解 非定常外源强迫 吸引集 算子方程}

在设计长期天气和气候数值预报模式之前, 必须了解大气系统演变的长期行为. 这是数 值试验所无法回答和解决的问题, 需进行一些基础理论的研究. 丑纪范 ${ }^{\left[{ }^{[13]}\right.}$ 首先讨论了定常 外源强迫下, $n$ 维空间中非线性大气系统向外源适应的问题. 之后, 又把结果推广到无穷维 Hilbert 空间 ${ }^{[4]}$. 对于实际大气系统, 外源强迫是非定常的, 在这种情形其结果是否成立, 这就是本文所主要讨论的问题.

\section{1 问题、前提和记号}

对于大尺度大气运动的偏微分方程组可化为如下的算子方程 ${ }^{[1 ~ 3,5]}$ :

$$
\left\{\begin{array}{l}
B \frac{\partial \psi}{\partial t}+(N+L) \psi=\xi, \\
B \psi=B \psi_{0}, \text { 当 } t=t_{0} \text { 时, }
\end{array}\right.
$$

其中 $B, L$ 为正定自伴算子, $N$ 为反伴算子, 偏微分方程组的非齐次项和边界条件都包括在 $\xi$ 中 $(B, N, L$ 的形式请参见文献 [1 3,5]).

本文考虑的是 $n$ 维欧氏空间中的情况, 因此, $B, L$ 为 $n$ 阶正定对称矩阵, $N$ 为 $n$ 阶反对称 矩阵. 当考虑定常或非定常外源强迫时, $\xi$ 分别为 $n$ 维常向量或变向量 $\xi_{t}$. 本文研究的是在 $R^{n}$ 中非定常外源强迫下, 大气运动当时间趋于无穷时的渐近性质的问题, 即相当于方程

$$
B \frac{\partial \psi}{\partial t}+(N+L) \psi=\check{\zeta}_{t}
$$

所决定的积分曲线当时间趋于无穷时的归宿.

在讨论之前, 需要一个假定和一些记号. 对于实际情况, 外强迫应是有界的, 即

$$
0<\left\|\xi_{t}\right\|^{2} \leqslant M<\infty \text {, }
$$

其中 $\|\cdot\|$ 表示范数.

1994-10-24 收稿, 1995-03-07 收修改稿

*国家教委博士点基金资助项目 
为方便起见, 令 $M_{0}=\left.M(t)\right|_{t=t_{0}}$ 表示相空间一个点, 那么初值等于 $M_{0}$ 的方程 (3) 的解为 $M(t)=\psi\left(M_{0}, t\right)$, 点集

$$
\gamma=\left\{\psi\left(M_{0}, t\right): t_{0} \leqslant t<\infty\right\} \text { 对某一切值 } M_{0},
$$

表示通过 $M_{0}$ 的路线,而点集

$$
V\left(t^{*}\right)=\left\{\psi\left(M_{0}, t\right): M_{0} \in V_{0}\right\}_{t=t^{*}}
$$

可视为一个映射, 它把 $V_{0}$ 映射成 $V, V_{0}, V \subset R^{n}$.

\section{2 主要定理}

引理 1 若椭球面 $E: \sum_{i=1}^{n}\left(\psi_{i}-a_{i}\right)^{2} / r_{i}=1$, 其中 $r_{i}, a_{i}(i=1,2, \cdots, n)$ 为常数, $r_{i} \in R^{+}, a_{i} \in R$, 则 在 $E$ 外的点 $\psi$, 有 $\sum_{i=1}^{n}\left(\psi_{i}-a_{i}\right)^{2} / r_{i}>1$;

在 $E$ 内的点 $\psi$, 有 $\sum_{i=1}^{n}\left(\psi_{i}-a_{i}\right)^{2} / r_{i}<1$.

引理 2 若椭球面 $E_{(A, r)}: \sum_{i=1}^{n}\left(\psi_{i}-a_{i}\right)^{2} / r_{i}=1$, 且 $A \in R_{1}^{n}, r \in R_{2}^{n}, r_{i} \in R^{+}(i=1,2, \cdots, n)$, 这里 $A=$ $\left(a_{1}, a_{2}, \cdots, a_{n}\right), r=\left(r_{1}, r_{2}, \cdots, r_{n}\right), R_{1}^{n}, R_{2}^{n}$ 均为有界闭集, 则

(1) $E=\bigcup_{R_{1}^{n}} E_{(A, r)}$ 为有界集;

其中 $\bigcup_{R_{1}^{n}} E_{(A, r)}$ 表示以 $R_{1}^{n}$ 内任一点 $A$ 为椭球心, 以 $r$ 为轴的所有椭球的并集;

(2) 在 $E$ 外的点 $\psi, \sum_{i=1}^{n}\left(\psi_{i}-a_{i}\right)^{2} / r_{i}>1$.

定理 在 (4) 式的假定下, 方程 (3) 的解满足, 存在有界闭集 $V_{0}$, 使

(1) 如果 $M_{0} \in V_{0}$, 那么 $\gamma \in V_{0}$;

(2) $\forall M_{0} \notin V_{0}$, 必存在一个 $\tau>0$, 点集 $V_{\tau} \in V_{0}$, 这里 $V_{\tau}=\left\{\psi\left(M_{0}, t\right): \tau \leqslant t<\infty\right\}$.

\section{3 定理证明}

以 $\psi$ 标乘 (3) 两边, 利用 $(\psi, N \psi)=0$, 得

$$
\frac{1}{2} \frac{d(\psi, B \psi)}{d t}=\left(\psi, \xi_{t}\right)-(\psi, L \psi)
$$

因 $L$ 为 $n$ 阶正定对称矩阵, 故有 $n$ 个大于零的特征值 $\lambda_{i}(i=1,2, \cdots, n)$, 相应的标准化的特征向 量记为 $\boldsymbol{e}_{i}(i=1,2, \cdots, n)$, 它们构成这个 $n$ 维空间的一组标准正交基, 故可令

其中

$$
\begin{aligned}
& \xi_{t}=\xi_{1}(t) \boldsymbol{e}_{1}+\xi_{2}(t) \boldsymbol{e}_{2}+\cdots+\xi_{n}(t) \boldsymbol{e}_{n}, \\
& a_{t}=a_{1}(t) \boldsymbol{e}_{1}+a_{2}(t) \boldsymbol{e}_{2}+\cdots+a_{n}(t) \boldsymbol{e}_{n},
\end{aligned}
$$

则

$$
a_{i}(t)=\xi_{i}(t) /\left(2 \lambda_{i}\right)
$$

$$
2 L a_{t}=\xi_{t} \text {. }
$$


令

$$
\begin{gathered}
\psi=\psi_{1} e_{1}+\psi_{2} e_{2}+\cdots+\psi_{n} e_{n}, \\
L e_{i}=\lambda_{i} e_{i},
\end{gathered}
$$

$\because$

$$
\therefore \quad\left(\psi, \xi_{t}\right)-(\psi, L \psi)=\sum_{i=1}^{n} \lambda_{i}\left\{a_{i}^{2}(t)-\left[a_{i}(t)-\psi_{i}\right]^{2}\right\} .
$$

考虑 $\left(\psi, \xi_{t}\right)-(\psi, L \psi)=0$ 的点集 $E_{1}$, 即满足

$$
\sum_{i=1}^{n} \frac{\left[\psi_{i}-a_{i}(t)\right]^{2}}{\sum_{j=1}^{n} \lambda_{j} a_{j}^{2}(t) / \lambda_{i}}=1
$$

的点集. 由于 (4) 式和 (10) 式知 $0<\left\|a_{t}\right\|^{2} \leqslant M_{1}<\infty, a_{t} \subset R_{\perp}^{n}, R_{1}^{n}$ 为一有界闭集. 同时, $\lambda_{i} \in R^{+}$且 有界, 故 $0<\left\|r_{t}\right\|^{2} \leqslant M_{2}<\infty, r_{t}=\left(r_{1}(t), r_{2}(t), \cdots, r_{n}(t)\right), r_{i}(t) \in R^{+}(i=1,2, \cdots, n)$, 所以, $r_{t} \subset R_{2}^{n}, R_{2}^{n}$ 为一 有界闭集. 令 $E=U_{R_{1}^{n}} E_{\left(a_{o}, r\right)}$ 是以 $R_{\perp}^{n}$. 内任一点 $a_{t}$ 为椭球心、以 $r_{t}$ 为轴的满足 $(15)$ 式的所有椭球的 并集. 由引理 2 知, $E$ 为有界集; 且 $E \supset E_{\perp}$, 于是由引理 2 知, 在 $E$ 外的点 $\psi$, 有

$$
\frac{d(\psi, B \psi)}{d t}<0
$$

设一有界闭集 $V_{0} \supset E$, 则在 $V_{0}$ 外的点 $\psi$ 必满足 (16) 式, 于是通过 $V_{0}$ 外任一点的路线必将 在某个时刻 $\tau$ 时跑到 $V_{0}$ 内来, 而通过 $V_{0}$ 内任一点的路线不会跑到 $V_{0}$ 外去. 显然满足 $V_{0} \supset E$ 的有界闭集是存在的. 故定理得证.

\section{4 结果讨论}

由以上讨论知, 对于非定常外源强迫满足 (4) 式的情况下, 当时间 $t$ 大于某个临界时间 $\tau$ 时, 大气系统将进人吸收点集 $V_{0}$ 内, $V_{0}$ 外的点对研究时间趋于无穷的渐近状态无关, 只有暂 态意义, 系统长时间的行为将只取决于有界闭集 $V_{0}$. 这表明我们所研究的长期天气或气候过 程实际是处在吸引子状态. 由于耗散系统由高维相空间收缩到低维吸引子的演化, 是一个归 并自由度的过程, 因此决定系统长期行为的有效自由度最终减少到有限个数. 利用长期天气 过程的这种性质, 就可以从理论上对非定常外源强迫下大尺度运动吸引子的维数做出估计, 这将有助于建立新的长期数值预报理论和计算方法, 对此我们将另文报道.

\section{参考文献}

1 Chou Jifan. Some General Properties of the Atmosphric Model: in H Space, $R^{\mathrm{n}}$ Space, Point Mapping, Cell Mapping. Proceedings of International Summer Colloquium on Nonlinear Dyamics of the Atmosphere. Beijing: Meteorological Press, 1986. $187 \sim 189$

2 丑纪范. 长期数值预报. 北京: 气象出版社, 1986. $66 \sim 78$

3 丑纪范. 大气动力学的新进展. 兰州: 兰州大学出版社, 1990. $68 \sim 73$

4 汪守宏, 黄建平, 㺲纪范. 大尺度大气运动方程组解的一些性质一定常外源强迫下的非线性适应. 中国科学, B 辑, 1989, (3): $328 \sim 336$

5 丑纪范. 初始场作用的衰珹与算子的特性. 气象学报, 1983, 41 (4): 385 392

6 曾庆存. 数值天气预报的数学物理基础. 北京: 科学出版社, 1979 